\title{
Implementasi Metode Weighted Product (WP) PadaSistem Pendukung Keputusan Pemberian Bonus Karyawan
}

\author{
Miranda Magdalena ${ }^{1}$, Fransiska Prihatini $\mathrm{S}^{* 2}$ \\ ${ }^{1,2}$ Program Studi Sistem Informasi, Fakultas Ilmu Komputer dan Rekayasa, Universitas \\ MultiData Palembang \\ e-mail: ${ }^{1}$ mirandamagd@mhs.mdp.ac.id, ${ }^{2}$ fransiskaps@mdp.ac.id
}

\begin{abstract}
Abstrak
PT SJP adalah perusahaan yang bergerak di bidang distributor semen. Perusahaan ini memiliki permasalahan yang terjadi pada saat proses pemberian bonus karyawan yaitu membutuhkan waktu yang cukup lama proses perhitungan karena jumlah karyawan yang cukup banyak dan perhitungan masih dilakukan secara manual. Hasil perhitungan juga tidak transparan dan ada kriteria yang terkadang tidak diperhitungkan perusahaan. Untuk itu dibuat sebuah sistem pendukung keputusan untuk membantu perusahaan dalam proses perhitungan bonus karyawan berdasarkan kriteria yang diinginkan perusahan dan menentukan nominal bonus karyawan berdasarkan perhitungan dengan metode Weighted Product (WP). Sistem ini dikembangkan dengan metodologi iteratif, dibangun berbasis website menggunakan Visual Studio Code dengan bahasa pemrograman PHP, serta MySQL sebagai DBMSnya. Sistem pendukung keputusan pemberian bonus karyawan ini dapat mengatasi masalah penentuan bonus karyawan dan mempercepat proses perhitungan bonus karyawan di PT SJP.
\end{abstract}

Kata kunci : Sistem Pendukung Keputusan, Bonus, Weighted Product.

\section{Abstract}

PT SJP is a company engaged in the cement distributor. This company has a problem thatoccurs during the process of giving employee bonuses, which takes a long time to process the calculation because of the large number of employees and the calculations are still donemanually. The calculation results are also not transparent and there are criteria that have not been taken into account by the company. For this reason, a decision support system was made to assist in the bonus calculation process based on the company's desired criteria and determine the nominal bonus based on calculations using the Weighted Product (WP) method. This system wasdeveloped with an iterative methodology, built based on a website using Visual Studio Code with the PHP programming language, and MySQL as the DBMS. This decision support system for presenting employee bonuses can solve the problem of employee bonuses and the process of calculating employee bonuses at PT SJP.

Keywords: Decision support system, Bonus, Weighted product.

\section{PENDAHULUAN}

$\mathrm{P}$ erkembangan teknologi semakin pesat dalam beberapa tahun terakhir, membuat manusia semakin termotivasi menciptakan dan mengembangkan teknologi baru dengan tujuan untuk membantu manusia agar dapat bekerja secara efektif $d$ an efisien. Dengan adanya pengembangan teknologi informasi dan komputer, banyak perusahaan yang berusaha untuk 
menerapkan sistem yang bersifat komputerisasi dalam upaya meningkatkan kinerja sesuai dengan kebutuhan perusahaan tersebut. Salah satu sistem yang diterapkan adalah sistem pendukung keputusan di mana sistem ini merupakan sistem interaktif yang dapat membantu perusahaan serta meningkatkan kinerja dalam pengambilan keputusan menggunakan data dan model yang ada [1].

Salah satu proses pengambilan keputusan yang terjadi dalam perusahaan yaitu pemberian bonus karyawan. Bonus merupakan pembayaran sekaligus yang diberikan karena memenuhi sasaran kinerja [2]. Perusahaan memberikan bonus kepada karyawan sebagai bentuk penghargaan dari perusahaan dengan tujuan menaikkan tingkat semangat karyawan dalam bekerja, meningkatkan loyalitas karyawan terhadap perusahaan, serta meningkatkan kesejahteraan karyawan terutama dalam kehidupan karyawan. Sebagaimana yang kita ketahui, karyawan merupakan aset utama perusahaan, karena tanpa partisipasi mereka aktivitas perusahaan tidak akan terjadi dan karyawan berperan aktif dalam merumuskan rencana, sistem, proses, dan tujuan yang ingin dicapai [3]. Implementasi sistem pendukung keputusan sudah pernah dilakukan pada berbagai bidang, misalnya pemilihan siswa berprestasi [4]. Kenaikan jabatan karyawan Plaza Asia [5]. Penerimaan bantuan rumah layak huni [6]. Pemberian bonus karyawan menggunakan metode AHP [7]. Evaluasi pemilihan pemenang pengadaan aset [8]. Menentukan status karyawankontrak menjadi karyawan tetap [9]. Penilaian kinerja dosen [10]. Pemilihan teller polling terbaik [11]. Kenaikan jabatan karyawan menggunakan metode SAW [12]. Rekrutment karyawan menggunakan metode SAW [13], dan lainnya.

PT SJP merupakan perusahaan yang bergerak di bidang perdagangan sebagai distributor semen dan cat dengan karyawan yang berjumlah 68 orang. Perusahaan akan memberikan gaji pokok kepada karyawan sebagai kompensasi dari kerja seorang karyawan, selain dari gaji pokok,perusahaan memberikan bonus kepada karyawan. Pemberian bonus pada perusahaan ini dilakukan sekali dalam 1 tahun, sekitar pertengahan tahun dan nominal bonus ini tidak selalu sama setiap tahunnya. Nominal bonus yang diterima setiap karyawan juga berbeda-beda tergantung dari beberapa kriteria yang telah ditetapkan perusahaan. Adapun kriteria yang telah ditetapkan untuk menjadi pertimbangan pemberian bonus yaitu lama bekerja, absensi/ ketidakhadiran, kinerja, dan surat peringatan.

Proses pengumpulan data karyawan dilakukan mulai dari mengumpulkan data lama bekerja dan surat peringatan. Kemudian, mengambil data absensi yang bisa didapat dengan bantuan alat finger print. Sedangkan data kinerja dapat dinilai oleh pimpinan atau kepala masing- masing divisi dan akan dilaporkan kepada HRD. Setelah mengumpulkan semua data yang diperlukan untuk melakukan perhitungan, HRD akan melakukan input pada data tersebut dan melakukan perhitungan yang memakan waktu cukup lama karena jumlah karyawan yang cukup banyak sehingga terkadang terjadi kesalahan sehingga diragukan keakuratan dan tidak transparan dari hasil tersebut. Hasil perhitungan terhadap kriteria tidak digunakan dalam proses pengambilankeputusan, seperti kriteria kinerja yang masih dinilai secara subjektif dan beberapa kriteria terkadang tidak diperhitungkan contohnya seperti absensi dan surat peringatan. Karyawan hanya dapat menerima paling banyak tiga kali surat peringatan dan catatan surat peringatan akan dihapus setiap tahun agar tidak mempengaruhi tahun berikutnya. Surat peringatan ini terkadang tidak diperhitungkan dalam proses pengambilan keputusan karena hanya sedikit karyawan yang melakukan pelanggaran atau bahkan tidak ada sama sekali. 


\section{METODE PENELITIAN}

Penelitian ini dilakukan dalam 4 langkah utama yang dapat dilihat pada Gambar 1.

\subsection{Pengumpulan Data}

Pengumpulan data dilakukan dengan melakukan wawancara kepada pihak perusahaan, observasi mengenai hal yang berhubungan dengan pemberian bonus karyawan, dan melakukan studi literatur pada penelitian yang terkait dengan sistem pendukung keputusan.

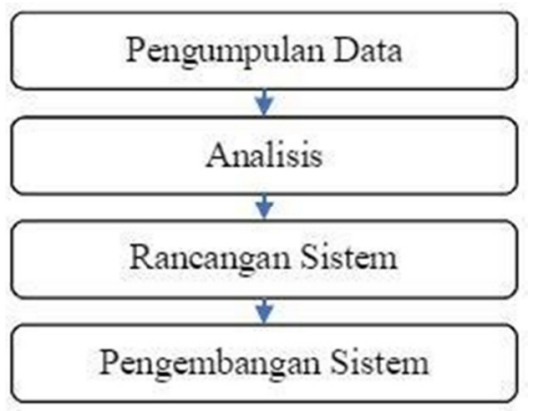

Gambar 1. Diagram Metode Penelitian

\subsection{Analisis}

Analisis permasalahan dilakukan dengan menggunakan kerangka PIECES yang terdiri dari Performance, Information, Economic, Control, Efficiency, dan Service dan dapat dilihat pada Tabel 1. Sedangkan analisis kebutuhan dirancang berdasarkan kebutuhan perusahaan dan akan digambarkan menggunakan use case diagram yang disajikan pada bagian selanjutnya.

Tabel 1. Analisis PIECES

\begin{tabular}{|c|c|l|}
\hline No. & PIECES & \multicolumn{1}{|c|}{ Permasalahan } \\
\hline 1. & Performance & $\begin{array}{l}\text { Proses perhitungan membutuhkan waktu yang cukup lama dan } \\
\text { seringterjadi kesalahan dan diragukan keakuratan proses tersebut. }\end{array}$ \\
\hline 2. & Information & $\begin{array}{l}\text { Perhitungan dilakukan dengan tidak transparan dan subjektif } \\
\text { mengakibatkan kurangnya informasi yang relevan terhadap } \\
\text { keputusan yang diambil. }\end{array}$ \\
\hline 3. & Economic & $\begin{array}{l}\text { Kesalahan dalam melakukan perhitungan bonus karyawan dapat } \\
\text { mengakibatkan menurunnya tingkat kepercayaan karyawan } \\
\text { terhadap } \\
\text { perusahaan atau bahkan pengunduran diri sehingga dapat } \\
\text { mempengaruhiaktivitas perusahaan. }\end{array}$ \\
\hline 4. & Control & $\begin{array}{l}\text { Perhitungan cukup sulit dilakukan terhadap karyawan yang cukup } \\
\text { banyakdengan kriteria penilaian yang digunakan. }\end{array}$ \\
\hline 5. & Efficiency & $\begin{array}{l}\text { Jumlah karyawan yang cukup banyak menyulitkan HRD dalam } \\
\text { proses perhitungan sehingga membutuhkan waktu yang cukup } \\
\text { lama dan kurang akurat karena sering terjadi kesalahan. }\end{array}$ \\
\hline 6. & Service & $\begin{array}{l}\text { Karyawan banyak yang kurang puas dengan hasil perhitungan } \\
\text { dan penilaian yang dilakukan perusahaan karena beberapa kriteria } \\
\text { seringdiabaikan dan tidak diperhitungkan. }\end{array}$ \\
\hline
\end{tabular}

Magdalena, et., al [Implementasi Metode Weighted Product (WP) PadaSistem Pendukung Keputusan Pemberian Bonus Karyawan] 


\subsection{Rancangan Sistem}

Pada tahap ini, perancangan terhadap sistem yang akan dikembangkan dilakukan. Rancangan sistem dibuat menggunakan Diagram Konteks, Diagram Dekomposisi, Data Flow Diagram (DFD), dan Entity Relationship Diagram (ERD).

\subsection{Pengembangan Sistem}

Tahap ini merupakan tahap pengembangan terhadap sistem menggunakan pengkodean. Sistem ini dibangun berbasis website dengan menggunakaan aplikasi Visual Studio Code denganbahasa pemrograman $P H P$ dan $M y S Q L$ sebagai tempat penyimpanan basis data.

\subsection{Metode Weighted Product (WP)}

Metode weighted product merupakan teknik yang menggunakan perkalian untuk menghubungkan rating atribut, rating setiap atribut harus dipangkatkan terlebih dahulu dengan bobot atribut yang bersangkutan atau biasa disebut proses normalisasi [14]. Rumus dari metode WP adalah sebagai berikut.

Penetuan nilai vektor W (Normalisasi Bobot)

\section{Penentuan nilai vektor $\mathrm{S}$}

$$
W j=\frac{W_{j}}{\sum W_{j}}
$$

\section{Penentuan nilai vektor $\mathrm{V}$}

$$
\begin{gathered}
S_{i}=\prod_{j=1}^{n} X_{i j}^{W j} \\
V_{i}=\frac{S_{i}}{\sum}(3)
\end{gathered}
$$

\section{HASIL DAN PEMBAHASAN}

\subsection{Kriteria Penilaian}

Adapun kriteria yang telah ditetapkan untuk menjadi pertimbangan pemberian bonus adalah sebagai berikut.

1. Lama Bekerja (Benefit) dengan subkriteria 1 tahun, 2 tahun, 3 tahun, 4 tahun, 5 tahun.

2. Absensi / Ketidakhadiran (Cost) dengan subkriteria $\leq 3$ hari, $4-12$ hari, $\geq 12$ hari.

3. Kinerja (Benefit) dengan subkriteria sangat buruk, buruk,, cukup, baik, sangat baik.

4. Surat Peringatan (Cost) dengan subkriteria 0, 1, 2 .

Tabel 2 memperlihatkan bobot kriteria yang akan diimplementasikan pada aplikasi yang akan dibuat, sedangkan Tabel 3 memperlihatkan rating kecocokannya.

Tabel 2. Bobot Kriteria

\begin{tabular}{|l|c|l|}
\hline \multicolumn{1}{|c|}{ Kriteria } & Bobot & Atribut \\
\hline Lama Bekerja & 4 & Benefit \\
\hline Absensi & 4 & Cost \\
\hline Kinerja & 5 & Benefit \\
\hline Surat Peringatan & 3 & Cost \\
\hline
\end{tabular}


Tabel 3. Rating Kecocokan

\begin{tabular}{|l|c|c|c|c|c|}
\hline & 2 & 4 & 6 & 8 & 10 \\
\hline Lama Bekerja & 1 & 2 & 3 & 4 & $\geq 5$ \\
\hline Absensi & $\leq 3$ Hari & & $4-12$ Hari & & $\geq 12$ Hari \\
\hline Kinerja & Sangat Buruk & Buruk & Cukup Baik & Baik & Sangat Baik \\
\hline Surat Peringatan & 0 & & 1 & & 2 \\
\hline
\end{tabular}

\subsection{Rancangan Sistem}

\subsubsection{Use case diagram}

Terdapat 4 aktor yang akan berinteraksi dengan sistem yaitu HRD, kepala divisi, pimpinan, dan karyawan yang memiliki hak akses nya masing-masing apabila berhasil melakukanlogin. Use case diagram yang dapat dilihat pada Gambar 2.

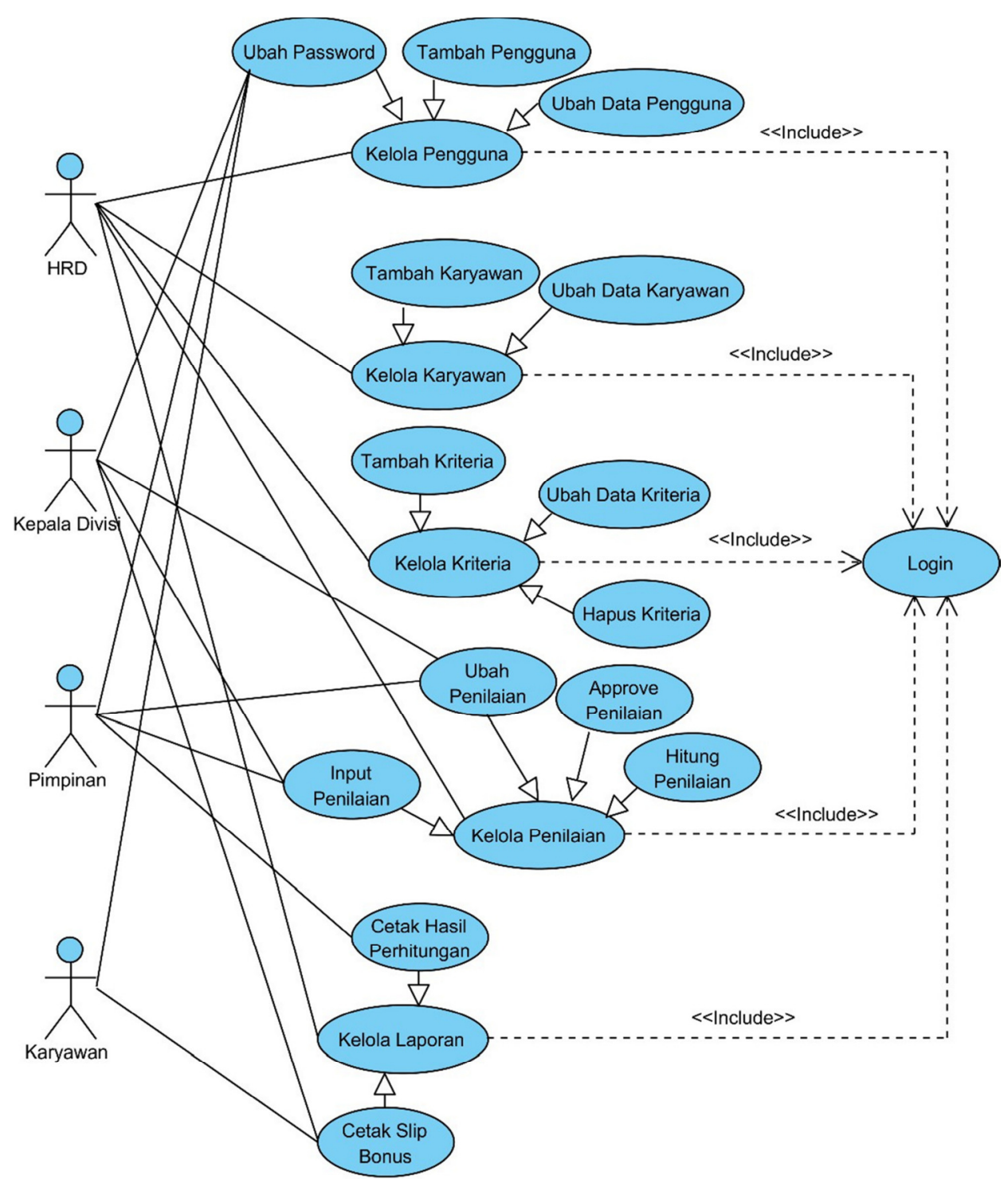

Gambar 2. Use Case Diagram

Magdalena, et., al [Implementasi Metode Weighted Product (WP) PadaSistem Pendukung Keputusan Pemberian Bonus Karyawan] 


\subsubsection{Data Flow Diagram (DFD)}

DFD menggambarkan aliran data yang mengalir di dalam sistem. Pada bagian ini dirancang diagram konteks yang merupakan konteks dan batasan sistem yang dapat dilihat pada Gambar 3. Dari diagram konteks, diuraikan rincian sistem menggunakan diagram dekomposisi yang dapat dilihat pada Gambar 4. Lalu masing-masing proses yang ada digambarkan pula ke dalam bentuk DFD rinci yang dapat dilihat pada Gambar 5.

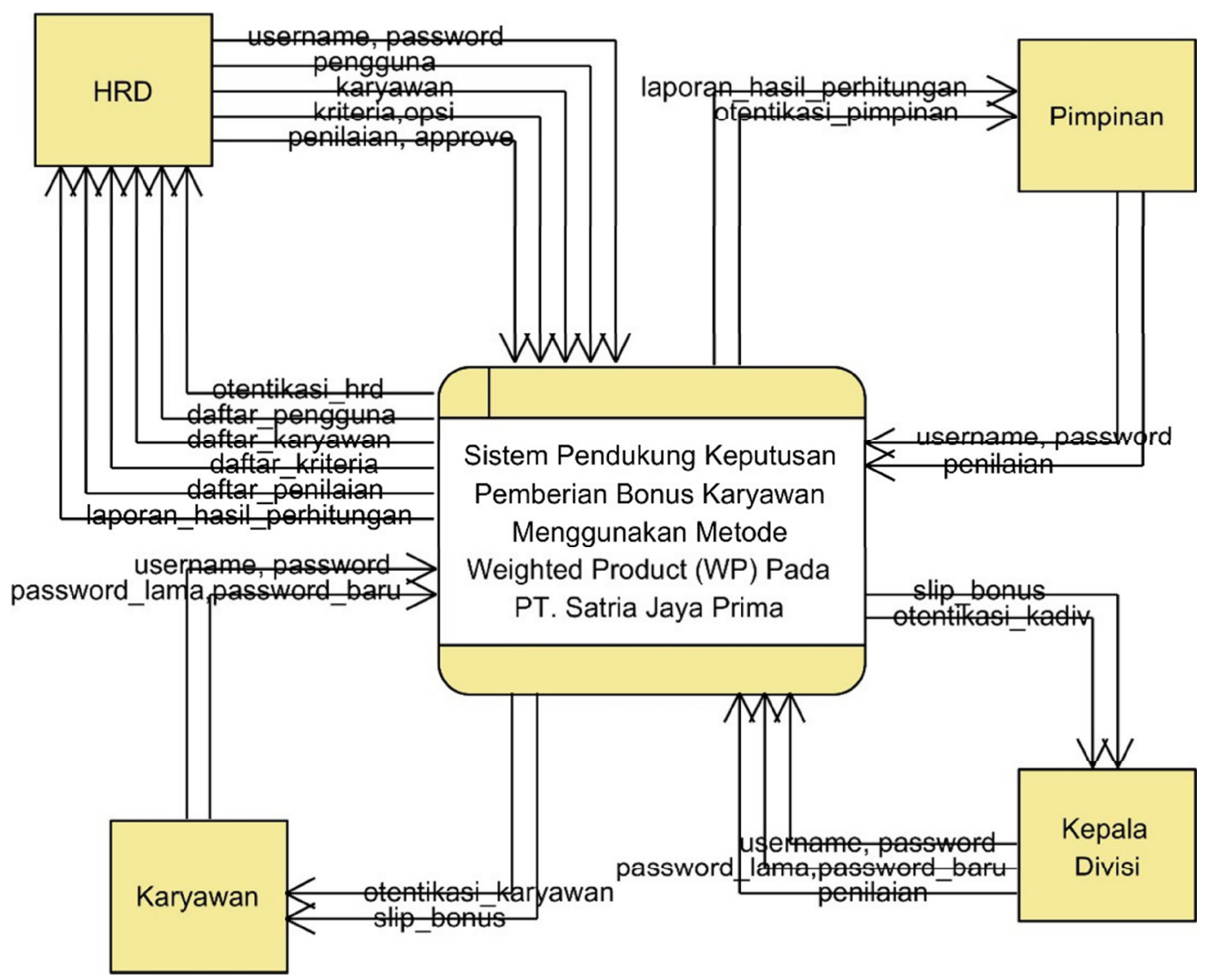

Gambar 3. Diagram Konteks

Berdasarkan Gambar 3, diperlihatkan terdapat 4 aktor pada sistem yang dirancang yaitu HRD, pimpinan, karyawan, dan kepala divisi. HRD harus melakukan login dengan memasukkan username dan password, setelah itu sistem akan melakukan otentikasi dan sistem akan menampilkan halaman beranda. HRD dapat melakukan perubahan terhadap data pengguna, data karyawan, data kriteria maupun opsi, data penilaian dan memberikan persetujuan pada penilaian kinerja karyawan. HRD juga dapat melakukan perhitungan penilaian sehingga sistem dapat menampilkan laporan hasil perhitungan.

Pimpinan harus melakukan login dengan memasukkan username dan password, setelah itu sistem akan melakukan otentikasi dan sistem akan menampilkan halaman beranda. Pimpinandapat melakukan perubahan pada data penilaian kinerja kepala divisi, pimpinan juga dapat melihatlaporan hasil perhitungan. 
Karyawan harus melakukan login dengan memasukkan username dan password, setelah itu sistem akan melakukan otentikasi dan sistem akan menampilkan halaman beranda. Karyawanjuga dapat melakukan perubahan terhadap password akses. Karyawan dapat melihat perhitungan terhadap kriteria dalam bentuk slip bonus.

Kepala divisi harus melakukan login dengan memasukkan username dan password, setelah itu sistem akan melakukan otentikasi dan sistem akan menampilkan halaman beranda. Kepala divisi juga dapat melakukan perubahan terhadap password akses. Kepala divisi dapat melakukan penilaian dan perubahan terhadap kinerja karyawan dan melihat perhitungan terhadapkriteria dalambentuk slip bonus.

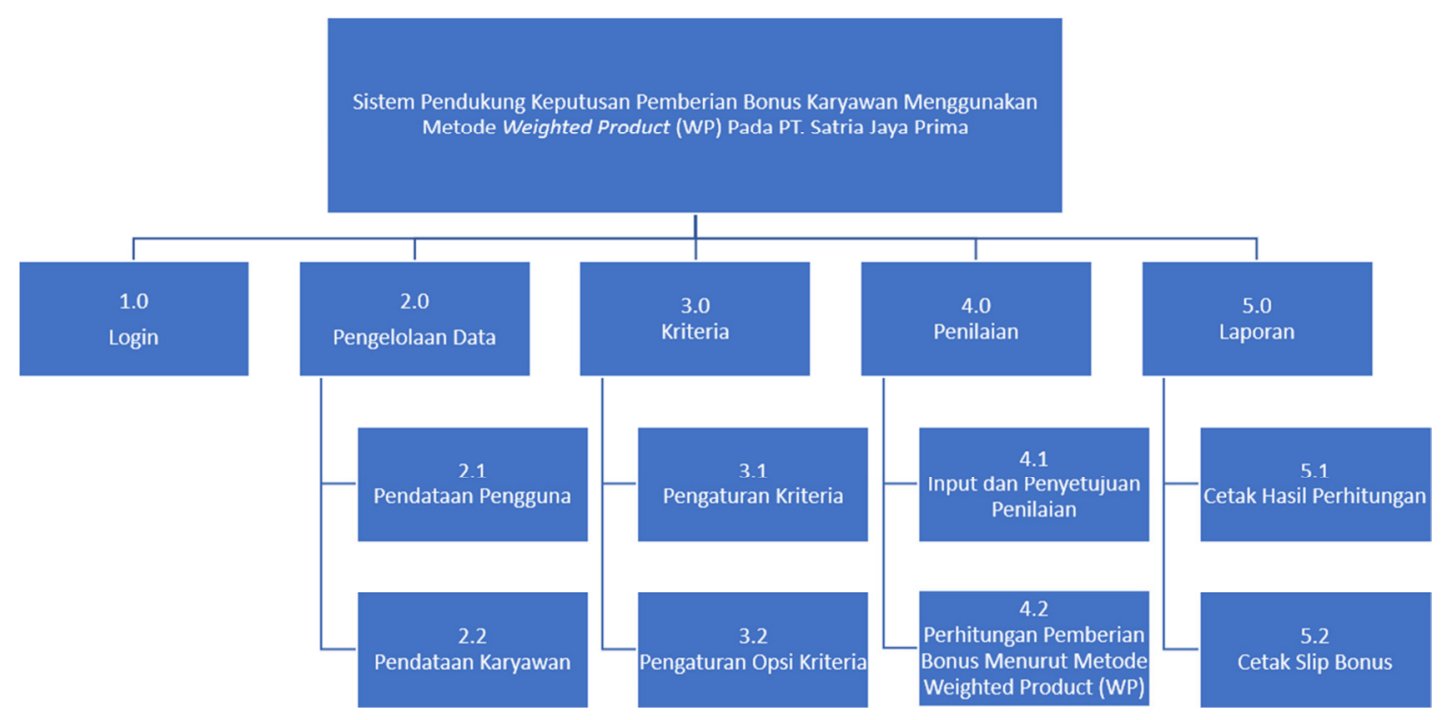

Gambar 4. Diagram Dekomposisi

Gambar 4 menunjukkan diagram dekomposisi dan menggambarkan bahwa sistem terbagi menjadi 6 bagian yaitu login, kelola pengguna, kelola karyawan, kelola kriteria, kelola penilaian, dan kelola laporan. 


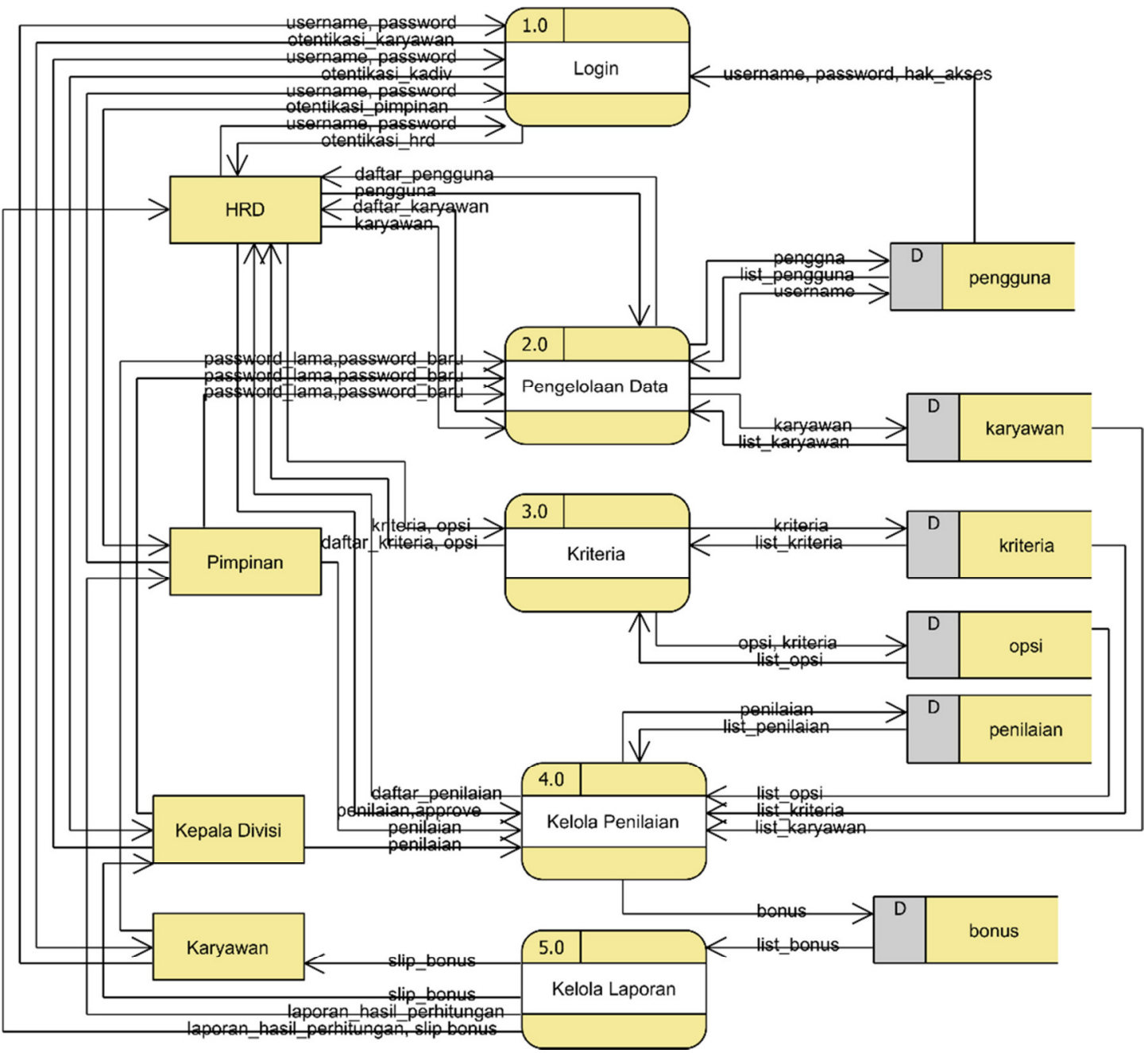

Gambar 5. Data Flow Diagram (DFD)

Setelah login, HRD dapat menampilkan daftar pengguna, serta melakukan pengelolaan terhadap data pengguna dan akan tersimpan pada tabel pengguna. HRD dapat menampilkan daftar karyawan serta melakukan pengelolaan terhadap data karyawan dan akan tersimpan pada tabel karyawan. HRD dapat menampilkan daftar kriteria dan opsi kriteria serta melakukan pengelolaan terhadap data kriteria atau data opsi kriteria dan akan tersimpan pada tabel kriteria dan opsi. HRD dapat menampilkan daftar penilaian, memberikan approve atau menolak penilaian, serta memberikan penilaian dan akan tersimpan pada tabel penilaian dan bonus. HRD dapat menampilkan laporan hasil perhitungan dan slip bonus pada periode tertentu yang diambil daritabel bonus.

Setelah login, pimpinan dapat melakukan perubahan terhadap password dan akan tersimpan pada tabel pengguna. Pimpinan dapat memberikan dan melakukan perubahan terhadappenilain dan akan tersimpan pada tabel penilaian. Pimpinan dapat menampilkan laporan hasil perhitungan pada periode tertentu yang diambil dari tabel bonus. 
Setelah login, kepala divisi dapat melakukan perubahan terhadap password dan akan tersimpan pada tabel pengguna. Kepala divisi dapat memberikan dan melakukan perubahan terhadap penilain dan akan tersimpan pada tabel penilaian. Kepala divisi dapat menampilkan slip bonus pada periode tertentu yang diambil dari tabel bonus.

Setelah login, karyawan dapat melakukan perubahan terhadap password dan akan tersimpan pada tabel pengguna. Karyawan dapat menampilkan slip bonus pada periode tertentu yang diambil dari tabel bonus.

\subsubsection{Entity Relationship Diagram (ERD)}

Dalam perancangan data sistem, penulis menggunakan Entity Relationship Diagram (ERD).

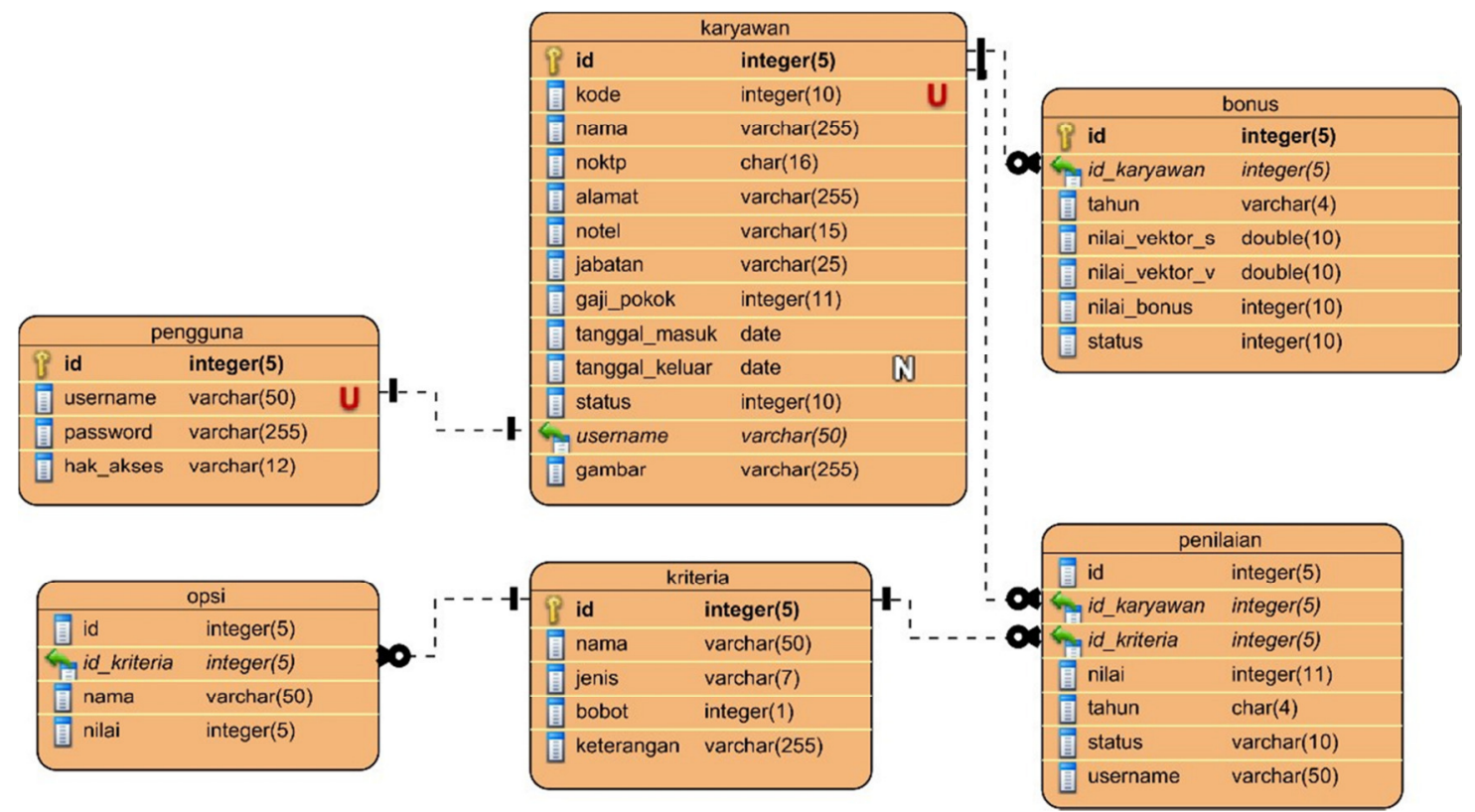

Gambar 6. Entity Relationship Diagram (ERD)

Tabel karyawan memiliki id sebagai primary key dan username sebagai foreign key. Foreign key tabel karyawan memiliki relasi one to one terhadap tabel pengguna. Primary key tabel karyawan memiliki relasi one to many terhadap tabel bonus. Primary key tabel karyawan memiliki relasi one to many terhadap tabel penilaian. Tabel penilaian memiliki id_kriteria sebagai foreign key dan memiliki relasi many to one terhadap tabel kriteria. Tabel kriteria memilki id sebagai primary key dan memiliki relasi one to many terhadap tabel opsi.

\subsection{Tampilan Antarmuka Aplikasi}

\subsubsection{Halaman Login}

Pengguna harus memasukkan username dan password untuk dapat mengakses sistem dansistem akan melakukan otentikasi. Halaman login dapat dilihat pada Gambar 7. 


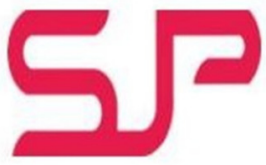

\section{SPK Bonus Karyawan \\ PT. Satria Jaya Prima}

\section{Username}

Password $\odot$

\section{Gambar 7. Halaman Login}

\subsubsection{Halaman Beranda}

Setelah pengguna berhasil melakukan login, pengguna akan diarahkan ke halaman beranda. Halaman beranda dapat dilihat pada Gambar 8

\section{PT. Satria Jaya Prima}

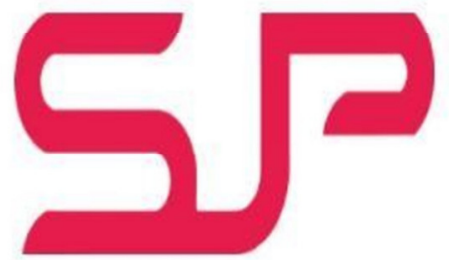

Gambar 8. Halaman Beranda

\subsubsection{Halaman Kriteria}

Halaman kriteria akan menampilkan data nama kriteria, jenis kriteria, bobot kriteria, keterangan, dan juga aksi yang berupa tombol ubah dan hapus. Pada halaman ini, pengguna jugadapat menambahkan kriteria baru. Halaman kriteria dapat dilihat pada Gambar 9. 


\begin{tabular}{|c|c|c|c|c|c|c|}
\hline \multicolumn{5}{|c|}{ List Kriteria } & \multicolumn{2}{|c|}{ Tambah Kriteria } \\
\hline \multicolumn{7}{|c|}{ Search: } \\
\hline$\# \uparrow$ & Nama & Jenis Kriteria & Bobot 11 & Keterangan & Aksi & \\
\hline 1 & Lama Bekerja & Benefit & 4 & Dalam Tahun & Ubah & Hapus \\
\hline 2 & Kinerja & Benefit & 5 & Tingkat kinerja karyawan & Ubah & Hapus \\
\hline 3 & Surat Peringatan & Cost & 3 & Jumlah surat peringatan yang diterima & Ubah & Hapus \\
\hline 4 & Jumlah Absensi & Cost & 4 & Jumlah ketidakhadiran karyawan dalam satu periode & Ubah & Hapus \\
\hline \multicolumn{7}{|c|}{ Showing 1 to 4 of 4 entries } \\
\hline & & & & & Previous & 1 Next \\
\hline
\end{tabular}

\section{Gambar 9. Halaman Kriteria}

\subsubsection{Halaman Karyawan}

Halaman karyawan akan menampilkan data kode karyawan, nama karyawan, jabatan, gaji pokok, status, dan juga aksi yang berupa tombol foto, ubah, dan nonaktif. Pada halaman karyawan, pengguna juga dapat menambahkan data karyawan baru. Halaman karyawan dapat dilihat pada Gambar 10.

\begin{tabular}{|c|c|c|c|c|c|c|c|c|c|c|}
\hline \multicolumn{7}{|c|}{ List Karyawan } & \multicolumn{4}{|c|}{ Tambah Karyawan } \\
\hline \multicolumn{11}{|c|}{ Search: } \\
\hline$\#+1$ & Kode & Nama & Jabatan & Gaji Pokok & Status 11 & Aksi & & & & \\
\hline 9 & SJP-01-012 & Aldi Alferi & Sales & Rp. $3,270,000$ & Aktif & Foto & Ubah & & Nonak & \\
\hline 21 & SJP-03-006 & Andreas Danny Agus Wahyudi & Logistik Gudang & Rp. $3,270,000$ & Aktif & Foto & Ubah & & Nonak & \\
\hline 5 & SJP-01-008 & Aris Putra & Supervisor & Rp. $3,270,000$ & Aktif & Foto & Ubah & & Jonak & \\
\hline 4 & SJP-01-002 & Charles & Supervisor & Rp. $3,270,000$ & Aktif & Foto & Ubah & & Nonak & \\
\hline 28 & SJP-02-012 & Dede Triawan & Admin Gudang & Rp. $3,270,000$ & Aktif & Foto & Ubah & & Vonak & \\
\hline 18 & S.JP-02-009 & Dedek Sri Wahyuni & Admin Penjualan & Rp. $3,270,000$ & Aktif & Foto & Ubah & & Nonak & \\
\hline 12 & SJP-01-018 & Dedy Setiawan & Sales & Rp. $3,270,000$ & Aktif & Foto & Ubah & & Jonak & \\
\hline 11 & SJP-01-006 & Febryan & Kolektor & Rp. $3,270,000$ & Aktif & Foto & Ubah & & Jonak & \\
\hline 10 & SJP-01-013 & Ferdy Firdaus & Kolektor & Rp. $3,270,000$ & Aktif & Foto & Ubah & & Jonak & \\
\hline 27 & SJP-04-004 & Fransiscus Aditya Wibowo & Admin IT & Rp. $3,270,000$ & Aktif & Foto & Ubah & & Nonak & \\
\hline \multicolumn{11}{|c|}{ Showing 1 to 10 of 30 entries } \\
\hline & & & & & & Previous & 1 & 2 & 3 & Next \\
\hline
\end{tabular}

Gambar 10. Halaman Karyawan 


\subsubsection{Halaman Laporan}

Halaman laporan akan menampilkan data kode karyawan, nama karyawan, nilai vektorV, nilai bonus, status, dan juga ranking. Halaman laporan dapat dilihat pada Gambar 11.

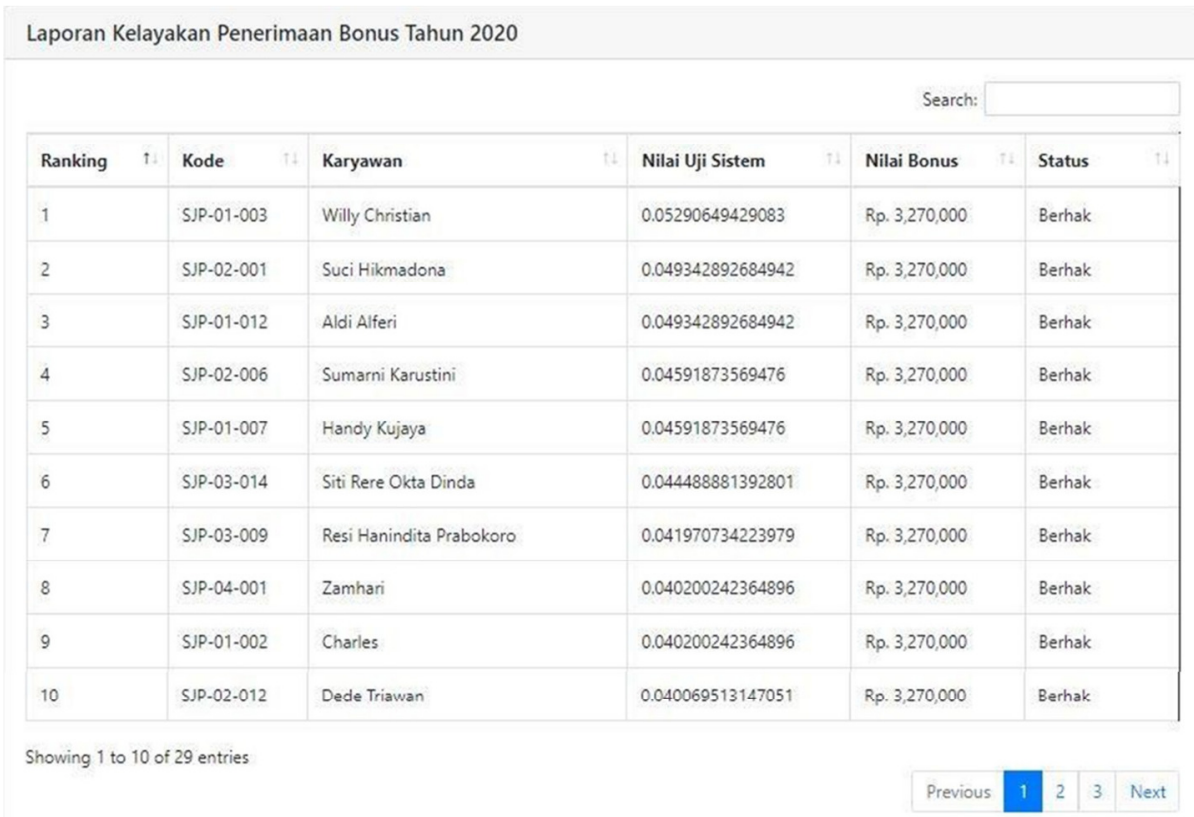

Gambar 11. Halaman Laporam

\section{KESIMPULAN DAN SARAN}

\subsection{Kesimpulan}

1. Dibangun sistem pendukung keputusan ini, karyawan yang mendapatkan bonus merupakan hasil perhitungan terhadap kriteria.

2. Sistem ini dapat melakukan perhitungan bonus secara transparan berupa slip bonus yang dapat dilihat seluruh karyawan.

3. Sistem pendukung keputusan ini dapat memperhitungkan semua kriteria yang dibutuhkan khususnya kriteria status peringatan yang sering diabaikan dalam proses pengambilan keputusan.

\subsection{Saran}

1. Diharapkan kepada PT SJP melakukan pemeliharaan terhadap sistem pendukung keputusan ini agar sistem ini dapat berjalan dengan baik dan dapat digunakan untuk waktuyang cukup lama.

2. Sistem pendukung keputusan ini dapat dikembangkan dengan fitur lain tidak hanya untuk perhitungan bonus karyawan. 


\section{DAFTAR PUSTAKA}

[1] Pratiwi, Heny., 2016, Buku Ajar Sistem Pendukung Keputusan, DeePublish, Yogyakarta.

[2] Henry, Simamora., 2010, Manajemen Sumber Daya Manusia, STIE YKPN, Yogyakarta.

[3] Hasibuan, Malayu SP., 2014, Manajemen SDM, Edisi Revisi, Bumi Aksara, Jakarta.

[4] Muslihudin, Muhamad, dan Dewi Rahayu. 2018, Sistem Pendukung Keputusan Siswa Berprestasi Menggunakan Metode Weighted Product, Jurnal TAM, Vol. 9, No. 2, hal $114-119$.

[5] Sambani, Egi Badar, Yoga Handoko Agustin, dan Rina Marlina, 2016, Sistem Pendukung Keputusan Kenaikan Jabatan Karyawan Plaza Asia dengan Menggunakan Metode WeightedProduct, Jurnal CSRID Journal, Vol. 8, No. 2, hal 121 - 130.

[6] Kusumawardani, Danik., 2014, Sistem Pendukung Keputusan Penerimaan Bantuan Rumah Layak Huni dengan Menggunakan Metode Weighting Product (WP), Fasilkom Udinus, Semarang.

[7] Manurung, Nuriadi., 2017, Sistem Pendukung Keputusan Pemberian Bonus Karyawan menggunakan Metode AHP, Jurnal Teknologi Infromasi, Vol.1 No. 1, hal 468 - 53.

[8] Nugraha, Fajar, Bayu Surarso, dan Beta Noranita, 2012, Sistem Pendukung Keputusan Evaluasi Pemilihan Pemenang Pengadaan Aset dengan Metode Simple Additive Weighting (SAW), Jurnal Sistem Infromasi Bisnis 02, hal 67 - 72.

[9] Sambani, Egi Badar, dan Fajar Nugraha, 2018, Sistem Pendukung Keputusan Untuk Menentukan Status Karyawan Kontrak Menjadi Karyawan Tetap Menggunakan Metode SMART, Jurnal Sistem Informasi dan Teknologi Informasi, hal 116 - 123.

[10] Agustin, Yoga Handoko, dan Hendra Kurniawan, 2015, Sistem Pendukung Keputusan Penilaian Kinerja Dosen Menggunakan Metode Weighting Product, MTI STMIK AMIKOM, Yogyakarta.

[11] Riyanto, E.A, dan Tuti Haryanti, 2017, Sistem Pendukung Keputusan Pemilihan Teller Pooling Terbaik pada PT. BCA Tbk. dengan Metode SAW (Simple Additive Weighting, JurnalPilar Nusa Mandiri, Vol 13 No. 1, hal 128 - 135.

[12] Sihotang, Fransiska Prihatini, dan Ferent Michaela, 2021, Sistem Pendukung Keputusan Kenaikan Jabatan Karyawan Dengan Simple Additive Weighting (SAW) Pada Dealer Mobil,Fakultas Ilmu Komputer dan Rekayasa, Universitas Multi Data, Palembang.

[13] Pratama, Angga., 2021, Perancangan dan Implementas Sistem Pendukung Keputusan Rekrutmen Karyawan pada PT Buana Sentosa Nusantasa Menggunakan Metode SAW, Fakultas Sarjana Ilmu Komputer dan Rekayasa, Universitas Multi Data, Palembang.

[14] Kusumadewi, S., 2006, Fuzzy Multi-Attribute Decision Making (FUZZY MADM), Graha Ilmu, Yogyakarta. 